\title{
Synthesis and application of polyaminoamide as new paraffin inhibitor from vegetable oil
}

\author{
Gang Chen*, Ying Tang and Jie Zhang
}

\begin{abstract}
In this work, a series of novel paraffin inhibitor, polyaminoamide (PAA), was designed and prepared by aminolysis and poly-condensation using soybean oil and canola oil as the raw material. The property of the PAAs as paraffin inhibitor was investigated, the results show several PAA samples are potent in paraffin inhibition, and PPC-2 is the most effective one. Besides, the paraffin crystal morphology analysis was carried out to provide the mechanism of paraffin inhibition.
\end{abstract}

\section{Background}

Paraffin in crude oil is mixture of hydrocarbons constituted of linear/normal chains, comprising mainly from 20 to 40 carbon atoms, in addition to alkanes with branched and cyclic chains. Paraffin crystals grow as temperature decreases, creating a crystalline net, which begins to trap the molecules of liquid hydrocarbon until the oil cannot flow $[1,2]$. The lowest temperature at which crude oil can still flow is generally known as the pour point. Therefore, it is very important to minimize the adverse effects of paraffin on the flow properties of crude oil.

Several options are available including stream heating, blending with lighter cutter stocks, mechanical scraping and use of chemical additives, among which pretreatment of the crude oil with flow improver (FI), pour point depressants (PPD) or paraffin inhibitors (PI) has received the greatest acceptance due to its simplicity and economy [3-5]. PIs can modify the size and shape of crystals and inhibit formation of large paraffin crystal lattices [6]. The typical PIs have a wax-like paraffinic part that can co-crystallize with paraffin forming components of oil and a polar component limiting the degree of co-crystallization [3,7]. Polyethylene derivatives are the most popular PIs, such as homo and copolymers of alpha olefins, ethylene-vinyl acetate copolymers, polyalkyl acrylates and methacrylates, alkyl esters of styrene-maleic anhydride copolymers and alkyl fumarate-vinyl acetate copolymers [3-5,7]. Although these polymers display perfect performance for many crud oil samples from global, PIs are very selective, that is, not all

\footnotetext{
* Correspondence: gangchen@xsyu.edu.cn

College of Chemistry and Chemical Engineering, Xi'an Shiyou University, Xi'an Shaanxi, 710065, China
}

additives are sufficiently effective for every crude oil [8], and the long molecular chain, large molecular weight and high thermo stability is a serious problem in oil refine process [9].

This paper describes the preparation and evaluation of a new kind of paraffin inhibitor (polyaminoamide, PAA) using vegetable oil as the raw material (shown as Scheme 1) by aminolysis and poly-condensation. In the structure of PAA, hetero atoms $(\mathrm{N})$ were introduced into the main chain to enhance the polar and reduce thermo stability of the main chain for the activer $\mathrm{C}-\mathrm{N}$ bonds compared with $\mathrm{C}-\mathrm{C}$ bonds. The performance of PAAs as paraffin inhibitors was tested, and the paraffin crystal morphology was also analysized to investigate the interaction between PAA and paraffin crystal.

\section{Results and Discussion}

\section{Paraffin inhibition in simulated crude oil}

The paraffin inhibition of PAA with the concentration of $0.5 \mathrm{mg} / \mathrm{ml}$ in simulated crude oil (a kerosene solution of $n$-paraffin) was investigated and the results were summarized in Figure 1.

It can be found that all PAA samples can exhibit the paraffin deposition. PPS-2, PPS-3, PPC-2 and PPC-3 are better inhibitions than other samples with the paraffin inhibition ratio more than $56 \%$, which indicate the base catalyst or higher temperature is important factor for good paraffin inhibition. The maximal paraffin inhibitions of PPS- 2 and PPC- 2 are $62.5 \%$ and $66.2 \%$ respectively. Then the effect of concentration of PPS-2 and PPC- 2 on the paraffin inhibition was investigated, and the results were shown in Figure 2. The figure shows that 


$$
\begin{aligned}
& \text { Scheme } 1 \text { Preparation of polyaminoamide (PAA). } \\
& \text { vegetable oil }
\end{aligned}
$$

PPS-2 and PPC-2 exhibit good inhibition to paraffin crystallization as the concentration was controlled in range of $0.1 \%$ to $0.4 \%$, and more inhibitor is ineffective to improve the inhibition further, in other word the proper amount of PPS-2 and PPC-2 as paraffin inhibiters is $0.4 \%$.

\section{Paraffin crystal morphology study}

As the crude oil temperature goes below the pour point, paraffin crystals will deposit and tend to plug lines and filters. Paraffin inhibitor, alternatively known as wax crystal modifier, can reduce the growth of the paraffin crystal or form smaller crystals of a higher volume to surface ratio. Besides, from the view of morphology, the paraffin inhibitor can modify the size and shape of crystals and inhibit formation of large paraffin crystal lattices $[6,10,11]$. The morphology of paraffin crystal in PPC-2 untreated/treated simulated crude oil was investigated in the following work, and the photos were shown in Figure 3 and 4.

From the photos, it was found the paraffin crystals with larger size in blank experiment, which is to create a crystalline net and trap the molecules of liquid hydrocarbon until the oil cannot flow. While the paraffin crystals are much shorter and in PPC-2 treated samples, which indicates PPC-2 has the capability to reduce the tendency of crystals to form three-dimensional network. Mechanism of modifiers on paraffin is not very clearly understood, but it is clear that they enhance crystal morphology. There is certainly a combination of different mechanisms involving nucleation, co-crystallization and adsorption. The long side chains of PIs are like the paraffin crystals, this part functions by providing nucleation sites and co-

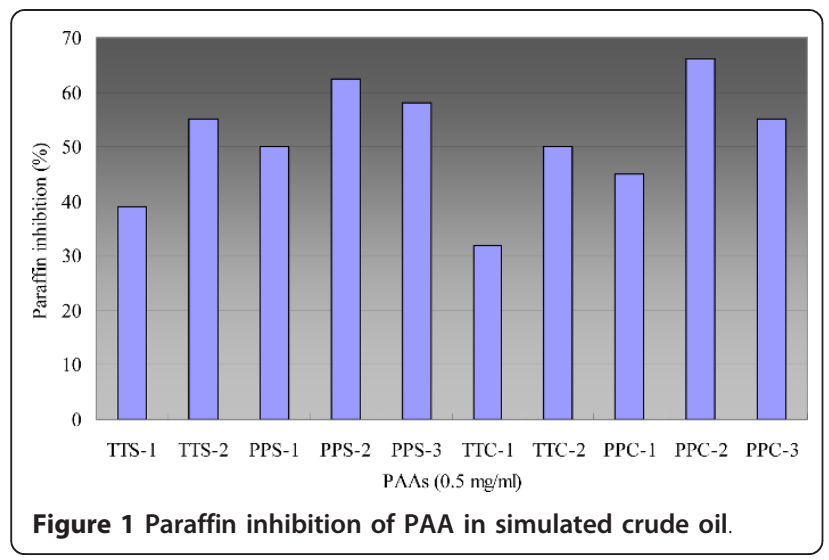

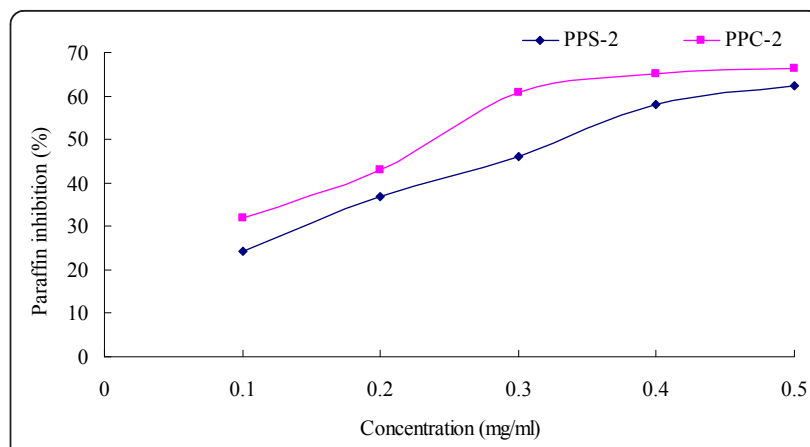

Figure 2 The effect of concentration of PPS-2 and PPC-2 on the paraffin inhibition.

crystallizing with the paraffin, while the other part of the structure, dissimilar to the paraffin crystals, blocks the extensive growth of the paraffin matrices $[6,10,11]$. This

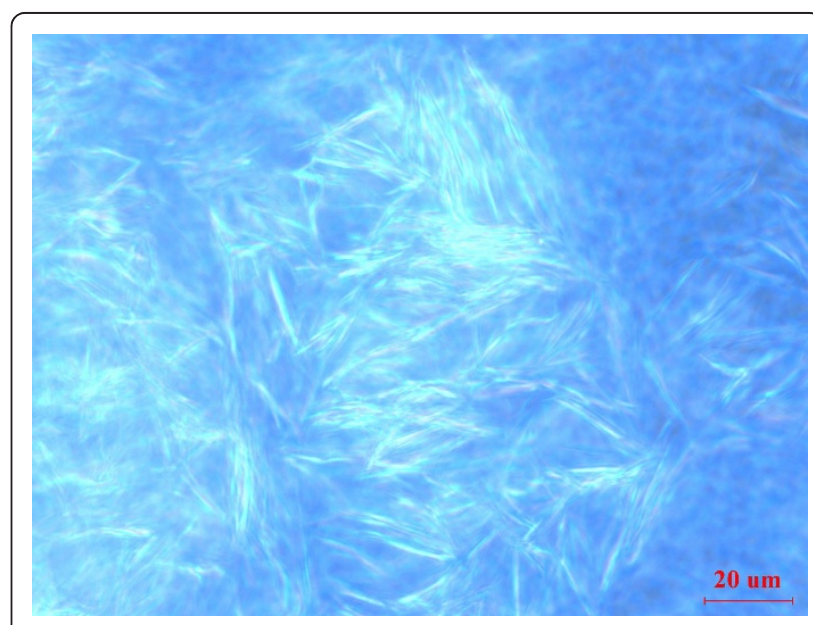

Figure 3 Photo of paraffin crystal in simulated crude oil.

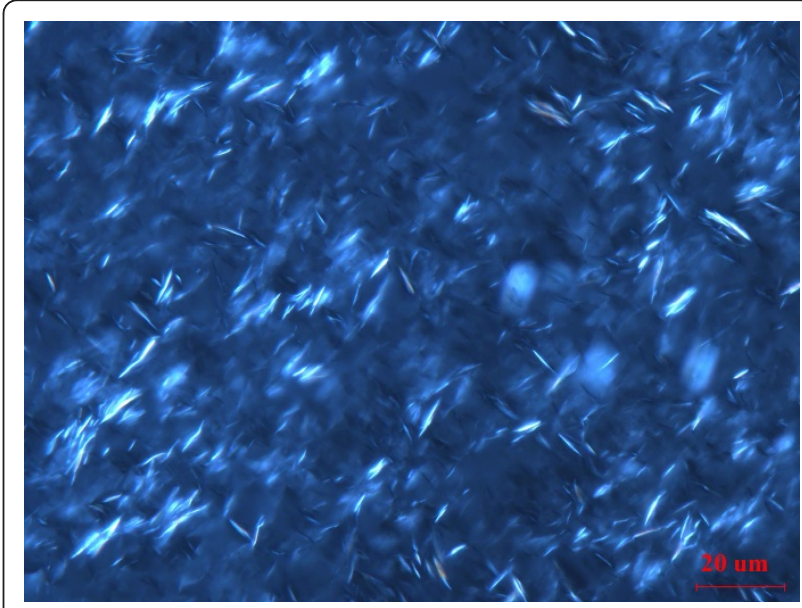

Figure 4 Photo of paraffin crystal in PPC-2 treated simulated crude oil. 
Table 1 PAA samples synthesized from vegetable oil

\begin{tabular}{|c|c|c|c|c|c|}
\hline Vegetable Oil & Amine & Solvent & Base & Aminolysis time/h & PAA \\
\hline soybean oil & triethylenetetramine & $\mathrm{EtOH}$ & - & 12 & $\pi$ TTS-1 \\
\hline soybean oil & triethylenetetramine & $\mathrm{EtOH}$ & $\mathrm{CaO}$ & 4 & TTS-2 \\
\hline soybean oil & polyethylene polyamine & $\mathrm{EtOH}$ & - & 12 & PPS-1 \\
\hline soybean oil & polyethylene polyamine & - & - & 12 & PPS-2 \\
\hline soybean oil & polyethylene polyamine & $\mathrm{EtOH}$ & $\mathrm{CaO}$ & 4 & PPS-3 \\
\hline canola oil & triethylenetetramine & $\mathrm{EtOH}$ & - & 12 & $\pi \mathrm{TC}-1$ \\
\hline canola oil & triethylenetetramine & $\mathrm{EtOH}$ & $\mathrm{CaO}$ & 4 & $\pi C-2$ \\
\hline canola oil & polyethylene polyamine & $\mathrm{EtOH}$ & - & 12 & $P P C-1$ \\
\hline canola oil & polyethylene polyamine & - & - & 12 & $\mathrm{PPC}-2$ \\
\hline canola oil & polyethylene polyamine & $\mathrm{EtOH}$ & $\mathrm{CaO}$ & 4 & PPC-3 \\
\hline
\end{tabular}

enables the bulk stream to remain pumpable, pourable and filterable. The PAAs have the characters to be efficient paraffin crystal modifiers with the long hydrocarbon chains derived from the vegetable oil and the hydrophilic part (amide groups). The function of PAAs has been to change the nature of the paraffin crystals and also to destroy cohesive forces between the crystals, thereby reducing the risk to form three-dimensional networks.

\section{Experimental}

\section{Preparation of polyaminoamide}

Pretreated canola oil or soybean oil [12] and triethylenetetramine/polyethylene polyamine solved in EtOH/ toluene were added in a flask with the 1.1: 1 molar ratio of the ester group to amino group. $10 \mathrm{wt} \% \mathrm{CaO}$ was added as catalyst (or no catalyst), and the mixture was stirred under refluxing for $4 \mathrm{~h}$ or $12 \mathrm{~h}$ for without catalyst. Then $\mathrm{CaO}$ was filtrated, and paraformaldehyde was added under stirring. After refluxing for another $4 \mathrm{~h}$, the solvent was then distilled off under reduced pressure, and the residue was PAA. The results were summarized in Table 1.

\section{Paraffin inhibition and paraffin crystallization in simulated crude oil}

The simulated crude oil was prepared by dissolving 150 g $n$-paraffin in $300 \mathrm{ml}$ kerosene, and PAA were added to prepare the comparison samples with different weight ratio. The paraffin inhibition was determined on an XZLA5 raw oil dynamic paraffin remover evaluator. The paraffin crystal of simulated crude oil with and without $0.5 \mathrm{mg} / \mathrm{ml}$ PAA1 was investigated using a BX41-P OLYMPUS polarizingmicroscope.

\section{Acknowledgements}

This work was financially supported by the grants from Scientific Research Program funded by Shaanxi Provincial Education Department (No.11JK0560, 11JK0591).

\section{Authors' contributions}

GC has conceived the study, formulated the research idea and prepared the manuscript draft version, YT carried out the chemical synthesis, and JZ participated in its design and coordination. All authors have read and approved the final manuscript.

\section{Competing interests}

The authors declare that they have no competing interests.

Received: 13 October 2011 Accepted: 8 December 2011 Published: 8 December 2011

\section{References}

1. Jorda MR: Paraffin deposition and prevention in oil wells. J Petrol Technol 1966, 18:1605-1612.

2. Truttle NR: High-pour-point and asphaltic crude oil and condensate. J Petrol Technol 1982, 35:1192-1196.

3. Chanda D, Sarmah A, Borthakur A, Rao KV, Subrahmanyam B, Das HC: Combined effect of asphaltenes and flow improvers on the rheological behaviour of Indian waxy crude oil. Fuel 1998, 77:1163-1167.

4. Al-Sabagh AM, Noor El-Din MR, Morsi RE, Elsabee MZ: Styrene-maleic anhydride copolymer esters as flow improvers of waxy crude oil. J Petrol Sci \& Eng 2009, 65:139-146.

5. Song YP, Ren TH, Fu XS, Xu XH: Study on the relationship between the structure and activities of alkyl methacrylate-maleic anhydride polymers as cold flow improvers in diesel fuels. Fuel Process Technol 2005, 86:641-650.

6. Newberry EM: Chemical effects on crude oil pipeline pressure problems. J Petrol Technol 1984, 36:779-86.

7. Kuzmić AE, Radošević M, Bogdanić G, Srića V, Vuković R: Studies on the influence of long chain acrylic esters polymers with polar monomers as crude oil flow improver additives. Fuel 2008, 87:2943-2950.

8. Siffeman RT: Flow properties of difficult-to-handle waxy crude oils. J Petrol Technol 1979, 31:1042-1050.

9. Institute Of Petroleum, Lucas AG: Modern petroleum technology, Volume 2, Downstream, 6th Edition. John Wiley and Sons, Ltd., England; 2000.

10. Holder $A G$, Winkler J: Crystal-growth poisoning of $n$-paraffin wax by polymeric additives and its relevance to polymer crystallization mechanisms. Nature 1965, 207:719-721.

11. Price CR: Flow improvers for waxy crudes. J Inst Petrol 1971, 57:106-109.

12. Tang $Y$, Meng M, Zhang J, Yong Lu: Efficient preparation of biodiesel from rapeseed oil over modified CaO. Applied Energy 2011, 88:2735-2739.

doi:10.1186/1752-153X-5-82

Cite this article as: Chen et al:: Synthesis and application of polyaminoamide as new paraffin inhibitor from vegetable oil. Chemistry Central Journal 2011 5:82. 